\title{
Regiodivergent reductive coupling of 2-substituted dienes to formaldehyde employing ruthenium or nickel catalyst: hydrohydroxymethylation via transfer hydrogenation $t$
}

\author{
Alexander Köpfer, ${ }^{a}$ Brannon Sam, ${ }^{b}$ Bernhard Breit ${ }^{\star a}$ and Michael J. Krische ${ }^{\star b}$ \\ The regioselective reductive coupling of paraformaldehyde to 2-substituted dienes at positions C1, C2 and \\ C3 was achieved using metal catalysts based on nickel, cationic ruthenium and neutral ruthenium, \\ respectively. Whilst $\mathrm{C} 1$ adducts predominate using dienes, silicon- or tin-substituted dienes exhibit C4 \\ regioselectivity - the first time that this regioselectivity has been observed for the coupling of \\ 2-substituted butadienes to aldehydes. Both nickel- and ruthenium-catalyzed processes avoid pyrophoric \\ or mass intensive reducing agents, using paraformaldehyde or isopropanol, respectively. These couplings \\ may be viewed as alternatives to diene hydroformylation, for which regioselective formation of \\ constitutionally isomeric products has not yet been achieved.
}

Received 22nd November 2012 Accepted 8th February 2013

DOI: $10.1039 / \mathrm{c} 3 s c 22051 f$

www.rsc.org/chemicalscience

\section{Research design and methods}

\section{Introduction}

While rhodium-catalyzed alkene hydroformylation is highly efficient, ${ }^{1}$ corresponding reactions of conjugated dienes ${ }^{2}$ generally provide mixtures of regioisomers or "double hydroformylation" byproducts. Although continued efforts have availed more efficient and selective rhodium catalysts for diene hydroformylation, ${ }^{2 m}$ only one regioisomeric product is accessible from a single diene reactant. Given these limitations, the reductive coupling of dienes to paraformaldehyde, an abundant C1-feedstock, was explored under the conditions of $\mathrm{C}-\mathrm{C}$ bond forming transfer hydrogenation. ${ }^{3}$ Here, we report that metal catalysts based on nickel, cationic ruthenium and neutral ruthenium promote regiodivergent reductive coupling at positions C1, C2 and C3 of the diene, respectively. Additionally, for 2-silyl- and 2-stannyl-substituted dienes, nickel catalysts were found to promote coupling predominantly at the C4-position. These processes provide an alternative to diene hydroformylation, for which regioselective formation of constitutional isomers has not yet been achieved (Fig. 1).

${ }^{a}$ Albert-Ludwigs-Universität Freiburg, Institut für Organische Chemie und Biochemie, Albertstrasse 21, 79104 Freiburg im Breisgau, Germany. E-mail: bernhard.breit@ chemie.uni-freiburg; Fax: +49 761-203-8715

${ }^{b}$ University of Texas at Austin, Department of Chemistry and Biochemistry, Austin, TX 78712, US. E-mail: mkrische@mail.utexas.edu; Fax: +1 512 471-8696

$\dagger$ Electronic supplementary information (ESI) available: Experimental procedures and spectroscopic data for all new compounds $\left({ }^{1} \mathrm{H}\right.$ NMR, ${ }^{13} \mathrm{C}$ NMR, IR, HRMS) including images of NMR spectra. See DOI: 10.1039/c3sc22051f
In initial studies on the ruthenium-catalyzed reductive coupling of higher aldehydes with 2-substituted dienes, neutral ruthenium catalysts were found to promote reductive coupling to higher aldehydes at the $\mathrm{C} 3$ position through hydrometallation of the less substituted olefin to form a nucleophilic 1,2-disubstituted $\pi$ allylruthenium intermediate RB (Fig. 2). ${ }^{\mathbf{4} 5}$ Based on this interpretation, it was postulated that neutral ruthenium complexes might catalyze the reductive coupling of 2-substituted dienes to paraformaldehyde at the $\mathrm{C} 3$ position. To test this hypothesis, myrcene 8 (100 mol\%) was exposed to paraformaldehyde $(200 \mathrm{~mol} \%)$ in the presence of $\mathrm{RuHCl}(\mathrm{CO})\left(\mathrm{PPh}_{3}\right)_{3}(5 \mathrm{~mol} \%)$, DPPB

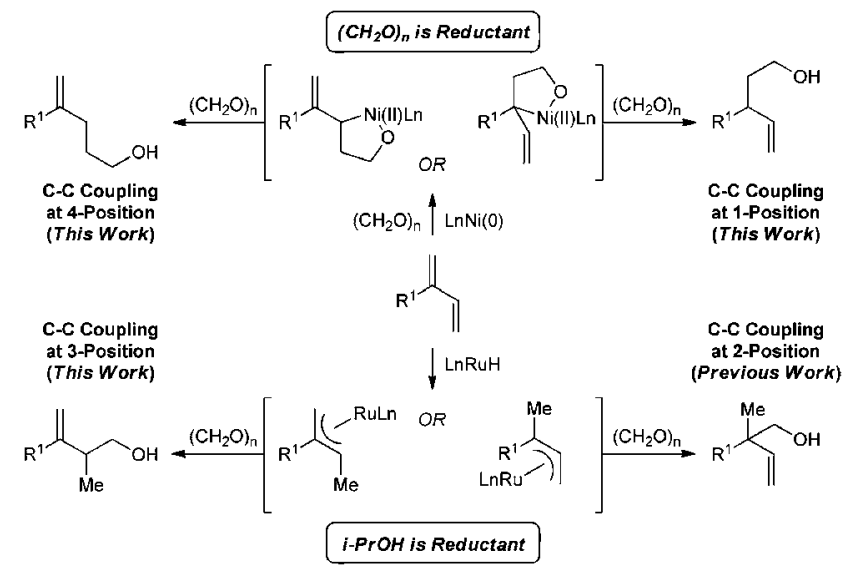

Fig. 1 Regioselective hydrohydroxymethylation of 2-substituted dienes via ruthenium- and nickel-catalyzed reductive coupling to formaldehyde. 


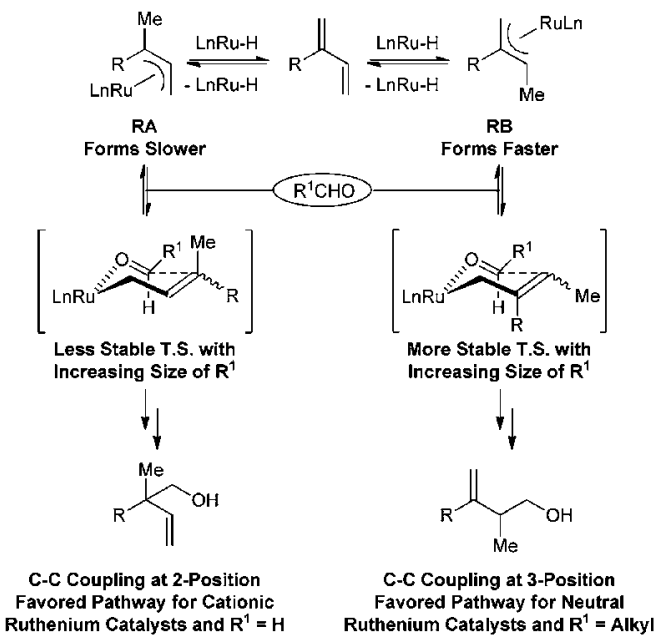

Fig. 2 Mechanistic basis for partitioning C2- and C3-regioselectivity in the ruthenium-catalyzed reductive coupling of 2-substituted dienes to formaldehyde.

(5 mol\%) and isopropanol (200 mol\%) in toluene at $95{ }^{\circ} \mathrm{C}$. The anticipated homoallylic alcohol $\mathbf{8 c}$ was obtained as a single regioisomer in $38 \%$ yield, along with a $15 \%$ yield of the corresponding formate ester. Formate formation occurs to the extent that paraformaldehyde contributes as a terminal reductant. ${ }^{6 b}$ While the use of paraformaldehyde as both terminal reductant and electrophilic partner is clearly desirable, low conversion to product was observed in the absence of isopropanol. In contrast, increased loadings of isopropanol (500 mol\%) suppressed formate formation ( $<3 \%$ yield), providing the homoallylic alcohol $8 \mathbf{c}$ in $50 \%$ isolated yield. Upon further variation of temperature and solvent, it was found that reactions conducted at $115{ }^{\circ} \mathrm{C}$ in dioxane provided the homoallylic alcohol $8 \mathbf{c}$ in $61 \%$ isolated yield, albeit with incomplete conversion. Withstanding minor adjustments to reaction temperature, these conditions proved general across a diverse set of 2-substituted dienes 1-11, delivering the homoallylic alcohols 1c-11c, respectively, in moderate to good yields and excellent levels of C3-regioselectivity (Table 1).

As described in the initial communication of this work, increased cationic character of the ruthenium(II) catalyst promotes reversible hydrometallation of 2 -substituted dienes, enabling access to the isomeric 1,1-disubstituted $\pi$-allylruthenium intermediates RA, which react with formaldehyde at the diene 2-position to furnish products incorporating all-carbon quaternary centers. ${ }^{6 b}$ Notably, use of cationic ruthenium(II) catalysts in couplings of 2-substituted dienes to higher aldehydes results in significant erosion of C2-regioselectivity, ${ }^{4 c}$ suggesting a Curtin-Hammett scenario is operative (Fig. 2). The generation of the ruthenium(II) catalyst, $\operatorname{RuH}\left(\mathrm{O}_{2} \mathrm{CC}_{7} \mathrm{~F}_{15}\right)$ (CO)(DPPB) $\left(\mathrm{PPh}_{3}\right)$, is easily achieved through the acid-base reaction of $\mathrm{RuH}_{2}(\mathrm{CO})\left(\mathrm{PPh}_{3}\right)_{3}$ and $\mathrm{HO}_{2} \mathrm{CC}_{7} \mathrm{~F}_{15}$ in the presence of DPPB. ${ }^{7}$ In the event, 2-substituted dienes 1-11 are converted to the primary neopentyl alcohols $\mathbf{1 b} \mathbf{b} \mathbf{1 1} \mathbf{b}$ in moderate to good isolated yields and with good to excellent levels of C2regioselectivity.

Having achieved regioselective reductive coupling of 2-substituted dienes 1-11 to formaldehyde at the C2- and
Table 1 Regiodivergent ruthenium- and nickel-catalyzed reductive couplings of 2-substituted dienes to formaldehyde ${ }^{a}$

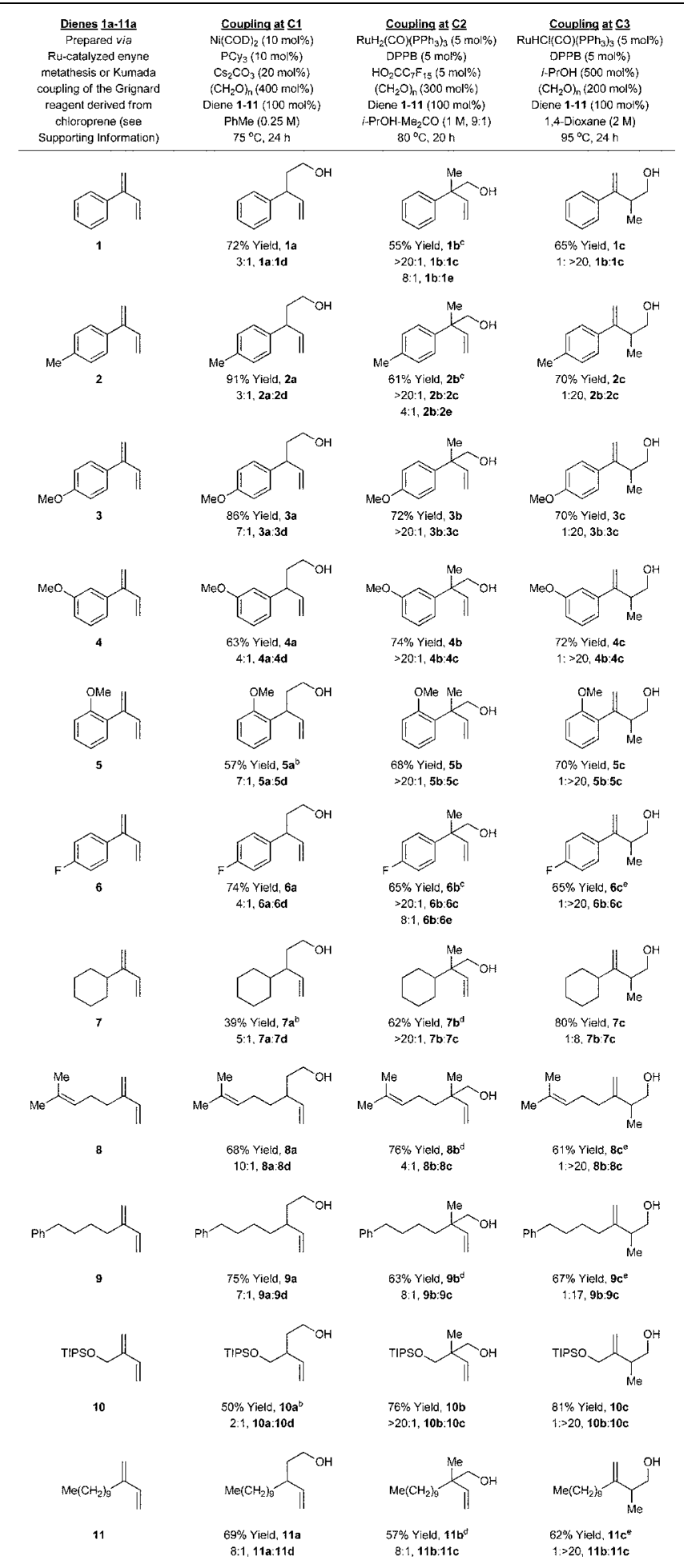

${ }^{a}$ Cited yields are of diastereomeric mixtures isolated by silica gel chromatography. Stereoisomeric ratios were determined by ${ }^{1} \mathrm{H}$ NMR analysis of crude reaction mixtures. See ESI for further experimental details. ${ }^{b} \mathrm{Ni}(\mathrm{COD})_{2}(20 \mathrm{~mol} \%), \mathrm{Cy}_{3} \mathrm{P}(20 \mathrm{~mol} \%) .{ }^{c} i$-PrOH$-\mathrm{Me}_{2} \mathrm{CO}(1 \mathrm{M}$, $1: 1) .{ }^{d}$ Reaction conducted at $90{ }^{\circ} \mathrm{C}$. ${ }^{e}$ Reaction conducted at $115{ }^{\circ} \mathrm{C} .{ }^{f}$ Product of over-reduction not present unless noted. 
C3-positions to form adducts $\mathbf{1 b}-\mathbf{1 1 b}$ and $\mathbf{1 c - 1 1 c}$, respectively, an analogous set of products 1a-11a derived from coupling to the diene C1-position was sought. Such C1-regioselectivity is evident in the nickel(0)-catalyzed diene-aldehyde reductive couplings pioneered by Tamaru, ${ }^{\mathbf{8}, 9}$ which are known to operate through a mechanism involving diene-aldehyde oxidative coupling. ${ }^{10}$ The major drawback of these couplings is the need for terminal reductants that are either pyrophoric or highly mass intensive (e.g. $\mathrm{ZnEt}_{2}, \mathrm{BEt}_{3}$ or $\left.\mathrm{HSiR}_{3}\right){ }^{7-9}$ Previously, conditions were identified for the nickel-catalyzed reductive coupling of alkynes to formaldehyde, using paraformaldehyde as both coupling partner and as reductant via transfer hydrogenation, thereby avoiding the use of additional reducing agents. ${ }^{6 \boldsymbol{b}, \boldsymbol{c}, \boldsymbol{1 1}} \mathrm{We}$ envisioned that applying these conditions to the coupling of 2substituted dienes with formaldehyde could lead to the desired C1 hydrohydroxymethylation products, without the drawbacks of the reducing agents employed in previous nickel(0)-catalyzed reductive couplings of dienes (Scheme 1). Upon exposure of myrcene 8 (100 $\mathrm{mol} \%)$ to paraformaldehyde (400 $\mathrm{mol} \%)$ in the presence of $\mathrm{Ni}(\mathrm{COD})_{2}(10 \mathrm{~mol} \%), \mathrm{PCy}_{3}(10 \mathrm{~mol} \%)$ and $\mathrm{Cs}_{2} \mathrm{CO}_{3}$ (20 mol\%) in toluene at $75{ }^{\circ} \mathrm{C}$, we were pleased to observe that the desired product of reductive coupling $8 \mathbf{a}$ was isolated in $68 \%$ yield with very good regioselectivity.

Under these conditions, 2-substituted dienes 1-11 were converted to products 1a-11a in good isolated yields with modest to good levels of C1- vs. C4-regioselectivity (Table 1). While screening for optimal conditions, we found that addition of $\mathrm{MeOH}$ or $\mathrm{H}_{2} \mathrm{O}(20 \mathrm{~mol} \%$ ) did not significantly influence the outcome of the reaction. This led us to observe that formalin could be used instead of solid paraformaldehyde in couplings to myrcene 8, providing the alcohol $8 \mathrm{a}$ in $60 \%$ isolated yield. As paraformaldehyde acts as both electrophile and reductant, generating formate, coupling products 1a-11a appear as the formate esters, which are cleaved in the course of isolation.

The partitioning of C1-adducts 1a-11a and C4-adducts 1d11d in the nickel-catalyzed reductive coupling of 2-substituted dienes 1-11 to formaldehyde can be understood as follows. As illustrated in the elegant work of Ogoshi, ${ }^{\mathbf{1 0}}$ oxidative coupling occurs reversibly in stoichiometric reactions of nickel(0) with dienes and aldehydes to provide isolable $\pi$-allylalkoxynickel(II) complexes that have been characterized by single-crystal X-ray diffraction analysis. In the case of isoprene, a 2-substituted diene, coupling at C1 was kinetically preferred (87 : 13, C1 : C4), but over time the isomeric ratio shifts to favor coupling at $\mathrm{C} 4$ (18: 82, C1 : C4). In analogy, the transient $\pi$-allylalkoxynickel(II) complexes $\pi$-allyl-NA and $\pi$-allyl-NB are proposed as reactive intermediates en route to C1-adducts 1a-11a and C4-adducts 1d-11d, respectively. The collective data suggest that under

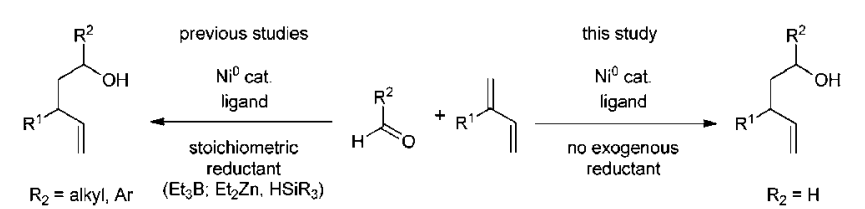

Scheme 1 Previously developed approaches requiring stoichiometric amounts of reducing agents, and the reductive coupling reported here. catalytic conditions, conversion of the kinetically preferred $\pi$-allyl-NA to product is more rapid than equilibration between $\pi$-allyl-NA and $\pi$-allyl-NB, resulting in a preference for coupling at the C1-position (Scheme 2).

Based on this analysis, diene substituents capable of weakening the newly formed $\mathrm{C}-\mathrm{C}$ bond might enable reversible oxidative coupling, and therefore equilibration between $\pi$-allylNA and $\pi$-allyl-NB, potentially leading to an increased proportion of the C4-adduct. ${ }^{4 f}$ Toward this end, silicon- and tin-substituted butadienes 12-14 were prepared, as hyperconjugation between the $\mathrm{C}-\mathrm{Si}$ or $\mathrm{C}-\mathrm{Sn} \sigma$-bond and the $\sigma^{*}$ orbital of the newly formed $\mathrm{C}-\mathrm{C}$ bond at $\mathrm{C} 1$ should weaken the latter and accelerate isomerization between $\pi$-allyl-NA and $\pi$-allyl-NB. As $\pi$-allyl-NB was anticipated to be thermodynamically more stable,$^{\mathbf{1 0}}$ formation of the C4-adducts 12d-14d should be favored. Gratifyingly, exposure of dienes 12-14 to nickel-catalyzed C-C coupling conditions does indeed provide a predominance of the C4-adducts 12d-14d (Table 2).

To demonstrate the synthetic utility of these products, we performed a Hiyama coupling of the bishomoallylic alcohol 13d with phenyl iodide. After 30 min this yielded $78 \%$ of the phenyl substituted C4 adduct 1d (Scheme 3). By this reductive coupling/Hiyama coupling sequence it is possible to obtain the missing $\mathrm{C} 4$ coupling product of the diene $\mathbf{1}$ selectively (Scheme 4). To date only one example of $\mathrm{C} 4$ selective reductive

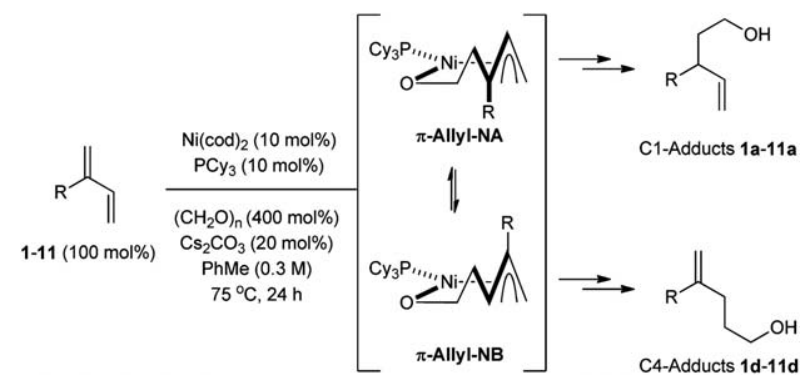

Scheme 2 Mechanistic basis for partitioning C1- and C4-regioselectivity in the nickel-catalyzed reductive coupling of 2-substituted dienes 1-11 to formaldehyde as supported by single-crystal X-ray diffraction analysis. ${ }^{12}$

Table 2 Nickel-catalyzed reductive coupling of dienes 12-14 to paraformaldehyde that display C4-regioselectivity ${ }^{a}$

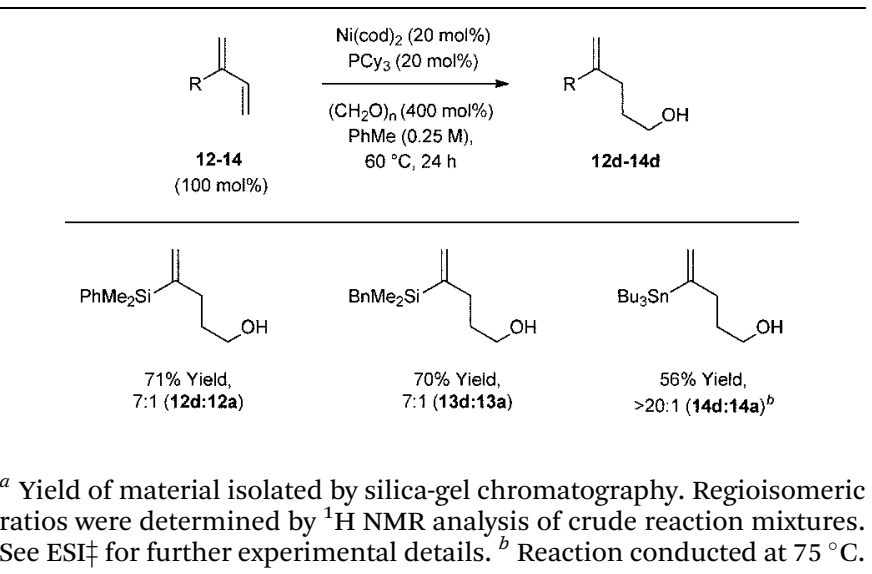




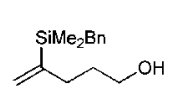

$13 d$

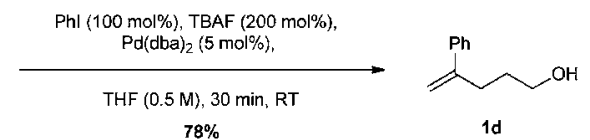

Scheme 3 Hiyama coupling leading to the desired C4 adduct.

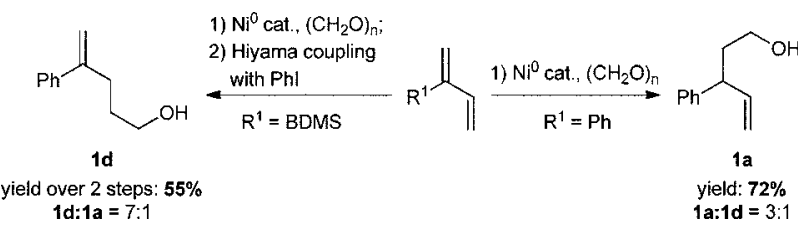

Scheme 4 Formation of C1 and C4 adducts of 1 by direct reductive coupling or a reductive coupling/Hiyama coupling sequence from silicon-substituted diene $\mathbf{1 3}$

coupling of 2-substituted butadienes has been reported, the ruthenium-catalyzed coupling of isoprene and myrcene to $\alpha$ hydroxyl esters. ${ }^{4 f}$ To the best of our knowledge, our nickelcatalyzed process represents the first $\mathrm{C} 4$ selective reductive coupling of 2-substituted butadienes to an aldehyde, yielding synthetically useful bishomoallylic alcohol building blocks.

To gain further mechanistic insight, isotopic labeling studies were conducted under standard conditions for coupling at the diene $\mathrm{C} 2$ - and C3-positions using deuterio-paraformaldehyde, $d_{8}$-isopropanol and both deuterio-paraformaldehyde and $d_{8}$-isopropanol (Fig. 3). For both sets of experiments, the observed patterns of deuterium incorporation clearly exclude diene hydroformylation-aldehyde reduction pathways. ${ }^{1 \boldsymbol{d}}$ Also, one can see that both paraformaldehyde and isopropanol contribute significantly as a hydride donor. The pattern of deuterium incorporation observed in the C3-selective coupling suggests hydrometallation modes A and $\mathbf{C}$ predominate and occur reversibly. Of particular note is the paucity of deuterium at the former diene C1-position, suggesting hydrometallation modes $\mathbf{D}$ and $\mathbf{E}$ occur infrequently. In contrast, under the conditions that promote $\mathrm{C} 2$-selective reductive coupling, the pattern of deuterium incorporation suggests rapid, reversible diene hydrometallation at all positions of the diene in advance of $\mathrm{C}-\mathrm{C}$ coupling. The observation of substantial quantities of deuterium at the diene C1-position suggests hydrometallation modes $\mathbf{D}$ and $\mathbf{E}$ are now readily traversed. These data are consistent with the hypothesis that enhanced cationic character and coordinative unsaturation associated with the $\mathrm{C}$-selective catalyst, $\mathrm{RuH}\left(\mathrm{O}_{2} \mathrm{CC}_{7} \mathrm{~F}_{15}\right)$ (CO)(DPPB) $\left(\mathrm{PPh}_{3}\right)$, enables access to hydrometallation modes and, hence, $\pi$-allylruthenium isomers, that are seldom accessed using neutral ruthenium catalysts.

Isotopic labeling studies also were conducted under standard conditions for nickel-catalyzed $\mathrm{C}-\mathrm{C}$ coupling at the diene C1-position using deuterio-paraformaldehyde (Fig. 4). Deuterium is incorporated exclusively and completely at the former diene C2-position. Additionally, no loss of deuterium is observed at the primary alcohol carbinol methylene. The absence of hydrogen at other positions suggests hydrometallative pathways are not operative. Rather, these data are consistent with $\mathrm{C}-\mathrm{C}$ bond formation via oxidative coupling, as

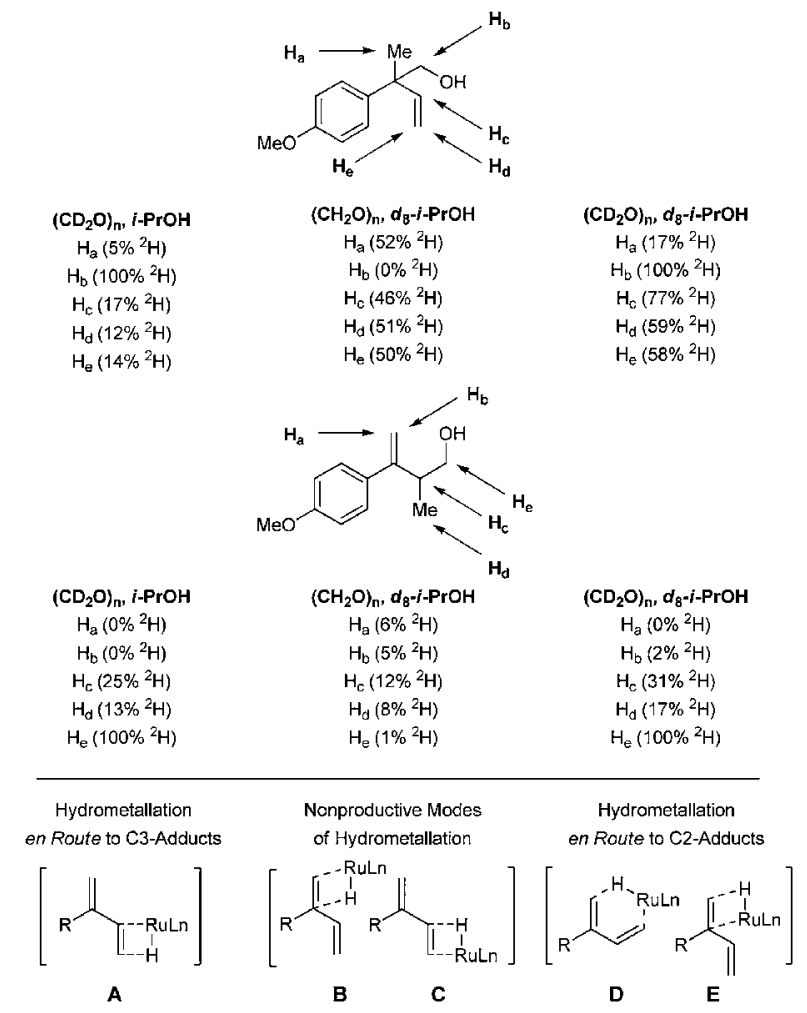

Fig. 3 Isotopic labeling studies involving ruthenium-catalyzed reductive coupling of diene $\mathbf{3}$ to paraformaldehyde at the C2- and C3-positions. The extent of ${ }^{2} \mathrm{H}$ incorporation was determined by ${ }^{1} \mathrm{H}$ and ${ }^{2} \mathrm{H}$ NMR analysis. The indicated values represent the average of two runs.

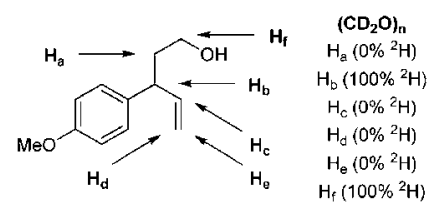

Fig. 4 Isotopic labeling studies involving nickel-catalyzed reductive coupling of diene $\mathbf{3}$ to paraformaldehyde at the $\mathrm{C} 1$-position. The extent of ${ }^{2} \mathrm{H}$ incorporation was determined by ${ }^{1} \mathrm{H}$ and ${ }^{2} \mathrm{H}$ NMR analysis. The indicated values represent the average of two runs.

established in stoichiometric reactions of dienes and aldehydes or ketones with $\mathrm{Ni}(\mathrm{COD}){ }^{\mathbf{1 0}}$

\section{Conclusions}

In summary, using metal catalysts based on nickel, cationic ruthenium and neutral ruthenium, regiodivergent reductive coupling of dienes 1-11 to paraformaldehyde was achieved at the diene C1, C2 and C3 positions, respectively. The first C4selective reductive coupling of 2-substituted butadienes with an aldehyde was achieved by changing the 2-substituent of the diene to silicon or tin. This yields useful building blocks, which can be further derivatized as demonstrated by a Hiyama coupling. For the nickel-catalyzed processes, a mechanism involving diene-formaldehyde oxidative coupling is operative and paraformaldehyde serves dually as reductant and carbonyl electrophile. For the ruthenium-catalyzed processes, diene 
hydrometallation serves to generate a nucleophilic allylruthenium intermediate, which undergoes addition to formaldehyde by way of the primary $\sigma$-allylruthenium haptomer. Whereas neutral ruthenium catalysts engage in kinetically controlled diene hydrometallation, the cationic ruthenium catalysts hydrometallate reversibly, thus enabling formaldehyde addition from regioisomeric $\pi$-allylruthenium intermediates.

\section{Acknowledgements}

Acknowledgmentis made to the Robert A. Welch Foundation (F0038), the NSF-ICC (CHE-1021640) and the NSF-DFG (BR 1646/ 6-1) for partial support of this research. The coauthors (A. K. and B. S.) contributed equally. Sonka Zeyner is acknowledged for skillful technical assistance.

\section{Notes and references}

1 For selected reviews on hydroformylation, see: (a) K. Weissermel and H.-J. Arpe, Industrial Organic Chemistry, Wiley-VCH, Weinheim, 2003, p. 127; (b) Rhodium catalyzed hydroformylation, ed. P. W. N. M. van Leeuwen, C. Claver, Kluver and Dordrecht, 2000; (c) B. Breit and W. Seiche, Synthesis, 2001, 1; (d) P. Kalck, Y. Peres and J. Jenck, Adv. Organomet. Chem., 1991, 32, 121.

2 For hydroformylation of conjugated dienes, see: (a) W. H. Clement and M. Orchin, Ind. Eng. Chem. Prod. Res. Dev., 1965, 4, 283; (b) B. Fell and H. Bahrmann, J. Mol. Catal., 1977, 2, 211; (c) H. Bahrmann and B. Fell, J. Mol. Catal., 1980, 8, 329; (d) C. Botteghi, M. Branca and A. J. Saba, J. Organomet. Chem., 1980, 184, C17; (e) P. W. N. M. van Leeuwen and C. F. Roobeek, J. Mol. Catal., 1985, 31, 345; (f) J. C. Chalchat, R. Ph. Garry, E. Lecomte and A. Michet, Flavour Fragrance J., 1991, 6, 178; $(g)$ S. Bertozzi, N. Campigli, G. Vitulli, R. Lazzaroni and P. J. Salvadori, J. Organomet. Chem., 1995, 487, 41; (h) T. Horiuchi, T. Ohta, K. Nozaki and H. Takaya, Chem. Commun., 1996, 155; (i) T. Horiuchi, T. Ohta, E. Shirakawa, K. Nozaki and H. Takaya, Tetrahedron, 1997, 53, 7795; (j) P. Liu and E. N. Jacobsen, J. Am. Chem. Soc., 2001, 123, 10772; (k) H. J. V. Barros, B. E. Hanson, E. N. dos Santos and E. V. Gusevskaya, Appl. Catal., A, 2004, 278, 57; (l) H. J. V. Barros, J. G. da Silva, C. C. Guimarães, E. N. dos Santos and E. V. Gusevskaya, Organometallics, 2008, 27, 4523; (m) A. L. Watkins and C. R. Landis, Org. Lett., 2011, 13, 164.

3 For selected reviews on $\mathrm{C}-\mathrm{C}$ bond forming hydrogenation and transfer hydrogenation, see: (a) R. L. Patman, J. F. Bower, I. S. Kim and M. J. Krische, Aldrichimica Acta, 2008, 41, 95; (b) J. F. Bower and M. J. Krische, Top. Organomet. Chem., 2011, 43, 107; (c) A. Hassan and M. J. Krische, Org. Process Res. Dev., 2011, 15, 1236.

4 For ruthenium-catalyzed diene-carbonyl transfer hydrogenative couplings beyond paraformaldehyde, see: $(a)$ F. Shibahara, J. F. Bower and M. J. Krische, J. Am. Chem. Soc., 2008, 130, 6338; (b) F. Shibahara, J. F. Bower and M. J. Krische, J. Am. Chem. Soc., 2008, 130, 14120; (c)
H. Han and M. J. Krische, Org. Lett., 2010, 12, 2844; (d) J. R. Zbieg, J. Moran and M. J. Krische, J. Am. Chem. Soc., 2011, 133, 10582; (e) J. R. Zbieg, E. Yamaguchi, E. L. McInturff and M. J. Krische, Science, 2012, 336, 324; (f) J. C. Leung, L. M. Geary, T.-Y. Chen, J. R. Zbieg and M. J. Krische, J. Am. Chem. Soc., 2012, 134, 15700; $(g)$ E. L. McInturff, E. Yamaguchi and M. J. Krische, J. Am. Chem. Soc., 2012, 134, 20628.

5 For related ruthenium-catalyzed diene-aldehyde C-C couplings, see: (a) T. Kondo, N. Hiraishi, Y. Morisaki, K. Wada, Y. Watanabe and T.-A. Mitsudo, Organometallics, 1998, 17, 2131; (b) S. Omura, T. Fukuyama, J. Horiguchi, Y. Murakami and I. Ryu, J. Am. Chem. Soc., 2008, 130, 14094. 6 For reductive coupling of allenes, dienes and alkynes to paraformaldehyde under the conditions of rutheniumcatalyzed transfer hydrogenation conditions, see: (a) M.-Y. Ngai, E. Skucas and M. J. Krische, Org. Lett., 2008, 10, 2705; (b) T. Smejkal, H. Han, B. Breit and M. J. Krische, J. Am. Chem. Soc., 2009, 131, 10366; (c) C. C. Bausch, R. L. Patman, B. Breit and M. J. Krische, Angew. Chem., Int. Ed., 2011, 50, 5687.

7 A. Dobson, S. R. Robinson and M. F. Uttley, J. Chem. Soc., Dalton Trans., 1975, 370.

8 For nickel-catalyzed intermolecular diene-aldehyde reductive coupling, see: (a) M. Kimura, A. Ezoe, K. Shibata and Y. Tamaru, J. Am. Chem. Soc., 1998, 120, 4033; (b) M. Takimoto, Y. Hiraga, Y. Sato and M. Mori, Tetrahedron Lett., 1998, 39, 4543; (c) M. Kimura, H. Fujimatsu, A. Ezoe, K. Shibata, M. Shimizu, S. Matsumoto and Y. Tamaru, Angew. Chem., Int. Ed., 1999, 38, 397; (d) M. Kimura, K. Shibata, Y. Koudahashi and Y. Tamaru, Tetrahedron Lett., 2000, 41, 6789; (e) M. Kimura, A. Ezoe, S. Tanaka and Y. Tamaru, Angew. Chem., Int. Ed., 2001, 40, 3600; (f) T.-P. Loh, H.-Y. Song and Y. Zhou, Org. Lett., 2002, 4, 2715; (g) Y. Sato, R. Sawaki, N. Saito and M. Mori, J. Org. Chem., 2002, 67, 656; (h) M. Kimura, A. Ezoe, M. Mori, K. Iwata and Y. Tamaru, J. Am. Chem. Soc., 2006, 128, 8559; (i) Y. Yang, S.-F. Zhu, H.-F. Duan, C.-Y. Zhou, L.-X. Wang and Q.-L. Zhou, J. Am. Chem. Soc., 2007, 129, 2248; (j) Y. Sato, Y. Hinata, R. Seki, Y. Oonishi and N. Saito, Org. Lett., 2007, 9, 5597.

9 For a recent review encompassing nickel-catalyzed dienealdehyde reductive coupling, see: M. Kimuara and Y. Tamaru, Top. Curr. Chem., 2007, 279, 173.

10 S. Ogoshi, K.-I. Tonomori, M.-A. Oka and H. Kurosawa, J. Am. Chem. Soc., 2006, 128, 7077.

11 For nickel-catalyzed alkyne-enal couplings that operate through internal hydrogen transfer from a transient hemiacetal, see: (a) A. Herath, W. Li and J. Montgomery, J. Am. Chem. Soc., 2008, 130, 469; (b) W. Li, A. Herath and J. Montgomery, J. Am. Chem. Soc., 2009, 131, 17024; (c) J. H. Phillips and J. Montgomery, Org. Lett., 2010, 12, 4556.

12 Isolable nickeladihydrofurans obtained upon intermolecular nickel mediated alkyne-aldehyde oxidative coupling have been characterized via single-crystal X-ray diffraction: S. Ogoshi, T. Arai, M. Ohashi and H. Kurosawa, Chem. Commun., 2008, 1347. 